PALAVRAS. Revista de Epistemología, Metodología y Ética del Psicoanálisis ISSN: 2468-9831

www.revistas.unlp.edu.ar/palavras

palavras@outlook.com.ar

Argentina

\title{
LA COMPLEJIDAD EN NUESTRA CLÍNICA E HISTORIA PSICOANALÍTICAS: ENTREVISTA CON LUIS HORNSTEIN
}

$10.24215 / 24689831 \mathrm{e} 014$

Maximiliano Azcona

Ariel Martínez

Cómo citar este artículo:

Azcona, M. \& Martínez, A. (2016). La complejidad en nuestra clínica e historia psicoanalíticas: entrevista con Luis Hornstein. Revista de Epistemología, Metodología y Ética del Psicoanálisis, 2, 164-183. Recuperado de www.revistas.unlp.edu.ar/palavras 


\section{LA COMPLEJIDAD EN NUESTRA CLINICA E HISTORIA PSICOANALÍTICAS: ENTREVISTA A LUIS HORNSTEIN}

\section{Maximiliano Azcona y Ariel Martínez *}

Luis Hornstein es médico psicoanalista. Recibió el Premio Konex de platino (década 1996-2006) en psicoanálisis. Codirigió (junto al Dr. Mauricio Goldemberg) el Centro de Estudios Psicoanalíticos de Caracas (1979-1983). Actualmente es coordinador científico de la Sociedad Psicoanalítica del Sur (SPS) y preside la Fundación de Estudios Psicoanalíticos (FUNDEP). Es autor de diversos libros: Teoría de las ideologías y psicoanálisis (1973), Introducción al psicoanálisis (1983), Cura psicoanalitica y sublimación (1988), AA.VV. Cuerpo, Historia, Interpretación (1991), Práctica psicoanalitica e historia (1993), Narcisismo: autoestima, identidad y alteridad (2002), Intersubjetividad y clinica (2003), Desafios de la práctica (compilador) (2004); Proyecto terapéutico (comp.) (2004), Las depresiones (2006), Autoestima e identidad (2011) y Las encrucijadas actuales del psicoanálisis (2013).

LH $=$ Luis Hornstein

$\mathbf{E}=$ entrevistadores

\section{E: ¿Cómo ve el estado actual del psicoanálisis en nuestro país, especialmente la formación de analistas y la investigación en la disciplina?}

LH: No soy muy optimista respecto al estado del psicoanálisis actual. Creo que hubo ciertas épocas, llamémosle dogmáticas, en el sentido de que hubo una corriente hegemónica que definía lo que es y lo que no es psicoanálisis. En la década del sesenta- setenta no ser kleiniano era no ser psicoanalista. La ruptura de la APA, posibilita un retorno a Freud y cierto eclecticismo. Yo hablo de eclecticismo con minúscula y eclecticismo con mayúscula, eclecticismo con minúscula es del que lee acríticamente y

\footnotetext{
* Universidad Nacional de La Plata y CONICET, Argentina. E-mails:
} azconamaxi@hotmail.com - arieles21@hotmail.com 
distribuye citas. El eclecticismo con mayúscula es propio de quien estudia la obra de Freud, Lacan, Klein, etcétera, y trata de rescatar de sus núcleos conceptuales aquello que se convierte en herramientas de trabajo, cierto eclecticismo con mayúscula contribuye al pluralismo crítico: el hecho de que pudiera haber discusiones entre colegas, cierta divergencia (no necesariamente oposición), para enriquecer nuestra práctica clínica. No tanto la fidelidad a un autor, no tanto la ilusión de que ya está todo escrito ni que todo consiste en recuperar lo que alguien antes pensó, sino que la clínica es como la pulsión: una exigencia de trabajo; y en ese sentido no nos podemos dar el lujo de desperdiciar pensadores heterogéneos que han contribuido al patrimonio compartido. Claro que dentro de eso hay opciones, están aquellos que sigan pensando que la teoría de base es Freud, aquellos que pensarán que es Klein, Lacan o Kohut; y aquellos que teniendo una teoría de base la van complejizando, enriqueciendo con autores que pueden brindarle instrumentos para abordar nuevas problemáticas clínicas. Y en ese sentido, ¿cuál es el diagnostico que hago de la época actual? Bueno, la década del setenta fue de cierto pluralismo, porque se rompió la hegemonía de la APA y recién se había empezado a conocer Lacan, porque los escritos estuvieron publicados en el '66 en Francia, pero a Argentina llegaron primero ciertos resúmenes hechos por Pontalís y otros autores, que nos dieron una pauta del primer Lacan, de aquel Lacan que se dedicó efectivamente a demostrar que la obra de Freud no estaba superada como se suponía. Acá se había establecido que Freud era como el bachillerato y que la Universidad del psicoanálisis era Klein. Lacan demostró que había que recuperar la complejidad de la obra freudiana, el famoso retorno a Freud. Por supuesto Lacan además fue construyendo su propia teoría y sus propias problemáticas institucionales; pero así y todo, la década del setenta fue una década de apertura. Luego vino el golpe, muchos nos tuvimos que ir del país y a partir de ahí se fue imponiendo el lacanismo. No digo que tenga una relación con la dictadura, porque el lacanismo se impuso en muchos países, pero sí que esa cierta 
tendencia a la abstracción facilitó que muchos psicoanalistas que estaban más comprometidos con actividades comunitarias se vieran limitados y reprimidos. Pero después vino el auge del lacanismo en la década del ochenta-noventa y yo diría que a partir de los últimos años recomienza un saludable pluralismo. En cuanto a la producción escrita. Por supuesto yo tengo una posición tomada. Para mí Lacan produjo un aporte, pero también fue un encierro para muchos: aquellos que entregaron su vida a descifrar a Lacan y como alguna vez dijo Castoriadis, "ningún gran

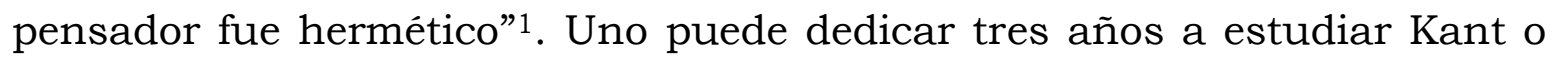
Hegel y lo entiende, pero es un poco sorprendente que haya gente que hace treinta años que está estudiando Lacan y no entiende las cosas fundamentales. O sea que ahí hay cierta retórica barroca que complejiza la adquisición de conceptos. Veo con preocupación que mucha gente joven, en este momento, tenga como punto de partida en su formación a Lacan y no a Freud. Había una frase que yo le decía a mi amigo León Rozitchner y que le molestaba mucho... Bachelard sostenía que "lo que es demasiado especializado para un filósofo es cultura general para un científico" ${ }^{2}$, pero yo lo aplico al psicoanálisis y digo: "el problema del psicoanálisis es que para la segunda generación de lacanianos o kleinianos, ya su cultura general es la obra de Lacan, ¿si? Y para la tercera generación ya es la obra de Miller, por lo cual se vuelve muy dificil el dialogo entre psicoanalistas. En ese sentido soy de los que procuran una formación freudiana de base y que cada persona pueda hacer una trayectoria personal ligada a su análisis, ligada a sus prácticas, a sus supervisiones y que pueda ir diferenciando dentro de las lecturas que va a haciendo, cuales son aquellos conceptos que son herramientas de trabajo; y que la guía (el GPS), no sea tanto lo que está de moda o el prestigio sino los que

${ }^{1}$ Cf. Castoriadis, C. (1992). El psicoanálisis, proyecto y elucidación. Buenos Aires: Nueva Visión.

${ }^{2}$ Cf. Bachelard, G. (1972/2005). El compromiso racionalista. Buenos Aires: Siglo XXI. 
transmiten herramientas para trabajar con los pacientes. Creo que, para que eso se produzca, todo joven psicoanalista tendria que tener por lo menos la oferta de distintas corrientes de pensamiento, es decir que esa persona pudiera supervisar un tiempo con un winnicotiano, luego un tiempo con un kohutiano o con una persona que esté dentro del psicoanálisis francés contemporáneo, donde me ubico yo, etc. Después de haber estudiado Lacan muchos años (muchos años no es toda mi vida), de haber estado en el Congreso de Caracas en el ochenta, de haber sido uno de los organizadores, me di cuenta de que me planteaba un limite en cuanto a mi trabajo clínico y me empecé a interesar por autores postlacanianos. Esto es una definición personal que tiene que ver con lo que sentí que me iba siendo más útil, más enriquecedor de mi teoría y de mi práctica.

\section{E: ¿Cuáles diria que fueron para usted los obstáculos principales que le presentaba la obra de Lacan?}

LH: A mi me hizo obstáculo ver como estaba funcionando en los ochenta el núcleo mismo del lacanismo, como funcionaba el poder, ¿ustedes saben por qué se hizo el Congreso de Caracas, en Caracas? Porque Lacan no podia venir a la Argentina, estaba muy mal visto en la intelligentsia francesa que un francés venga a un país con una dictadura sangrienta como era Argentina. Entonces Caracas era el territorio democrático, donde Miller decidió hacer valer su herencia. Nadie podía venir a Argentina a un congreso hasta que no cayera el gobierno militar.

\section{E: ¿Cree que de no haber sido por la dictadura el congreso hubiera sido acá entonces?}

LH: Con seguridad, el lugar natural era Buenos Aires; además en ese congreso el ochenta por ciento eran argentinos. Esto que digo es 
explicitado por Miller, no es un invento mío, por supuesto. Ahí vi un tipo de funcionamiento autocrático y yo me había ido del fascismo en Argentina, por lo que no quería entrar en un sistema fascista de nuevo. Cuando digo esto, me refiero concretamente a que hubo censura de trabajos en ese congreso... lo recuerdo sobre ciertas frases un poquito provocativas..." lo que se jugaba ahi era el pasaje de Lacan a Miller", etcétera, etcétera. Pero esto es un problema político. Mis restricciones a la entrega de mi intelecto al mundo lacaniano es que yo descubrí que me daba más instrumentos para trabajar el primer Lacan, el que planteaba la historización, la búsqueda de sentido; que el Lacan que vino después del sesenta, digamos, que no me daba respuestas a mi clínica... más bien era una fuga a la abstracción a partir de los grandes conceptos, castración, Edipo, etcétera... y que planteaba lo que él consideraba un psicoanálisis puro, un análisis propiamente dicho, que era el análisis de los psicoanalistas... y que descalificaba, la dimensión terapéutica del psicoanálisis como si Freud no hubiera tenido siempre claro que el psicoanálisis más a allá de ser un método de investigación, era un procedimiento terapéutico; como si Freud no hubiera escrito en el año 37', en Análisis terminable e interminable, que los dos requisitos para comenzar un análisis eran un monto de sufrimiento y de curiosidad. Lacan oponía el cobre del análisis terapéutico versus el oro del análisis didáctico, análisis que no tenía intenciones terapéuticas. Me parece que estaba invirtiendo la cuestión. Freud oponía el cobre con la sugestión al análisis pero desde Lacan todo lo que podía considerarse intención terapéutica era visto como una escoria que perturbaba el verdadero análisis. Para Freud el análisis debía ocuparse de inhibiciones, sintomas y angustia. Entonces, el descuido de la dimensión terapéutica y el uso de cierta fuga a la abstracción, me hicieron ver que los conceptos lacanianos no me ayudaban a trabajar mejor. Yo siempre lo digo, el paciente es una exigencia de trabajo mientras que el creyente es una exigencia de ritual. Mucho del psicoanálisis argentino se hacía en un ámbito de fuertes creencias y uno lo 
que tenía que hacer es cumplir con el ritual de moda; si el ritual de moda era hablarle al paciente, a cada palabra darle una palabra... o si el ritual de moda era quedarse callado durante unas sesiones, el estudiante venia acá a cumplir con su ritual, con lo que le enseñaban en la facultad... y el paciente que no pertenecía a la cultura psi, como pasaba en Caracas, no toleraba estas extravagancias. Los paciente que tal vez tengan ustedes hoy La Plata son pacientes que exigen de parte del analista no una pose simplemente sino un aporte donde haya algo de la subjetividad del analista puesto en juego, de la creatividad del analista puesta en juego y que no sea simplemente un recitador de clichés... entonces bueno, esa es un poco mi historia del alejamiento del lacanismo... lo escribí en algunos lados $^{3}$. Lo cual no quiere decir que, al mismo tiempo, no tenga que señalar lo contrario: que Lacan permito al psicoanálisis francés un salto cualitativo, porque después de él vinieron André Green, Piere Aulagnier, Jean Laplanche, Joyce McDougall, Jean-Bertrand Pontalis, etc. que implicaron una lectura mucho más rigurosa de Freud; esa es la diferencia del psicoanálisis poslacaniano con los psicoanalistas americanos o ingleses. En ese sentido el mérito de Lacan se basa más bien en su insistencia en hacer leer a Freud y buscar en la obra de Freud ciertos aspectos que habian quedado opacadas. Entonces, tenemos tres ejes: Lacan productor de una teoría nueva, Lacan como jefe de una institución, Lacan como un lector de Freud. Yo creo que como lector de Freud fue muy rico, en cuanto al Edipo, al lugar de la palabra o a la simbolización; y un Lacan que luego se fue yendo hacia una suntuosa pedagogia... y hacia un grupo que fue funcionando cada vez más como una secta. El verdadero problema es el Lacan institucional, es el Lacan que propiciaba el pase. En "Las encrucijadas del psicoanálisis" (FCE, 2013) me extendí sobre estas cuestiones.

3 Cf. Las depresiones (Paidós, 2006) y Las encrucijadas actuales del psicoanálisis (FCE, 2013). 


\section{E: Ese carácter sectario al que Ud. se refiere pareciera sintonizar bastante con lo que Freud consideraba que el psicoanálisis no deberia aspirar a ser: una cosmovisión.}

LH: Hay algunos que todavía hoy tienen respuesta para todo... Si vos lees lo que algunos analistas escriben en algunos diarios, es impresionante: se sienten con derecho a cuestionar a Marx, a Foucault, a Badiou sienten que poseen una cosmovisión superadora de todas las ciencias sociales juntas, de la política, de la filosofía. Mientras que Freud se ocupó mucho de decir que el psicoanálisis es apenas un fragmento del campo de la problemática psíquica. Son dos posiciones: el que quiere una teoría que le de certezas sobre todo y, por otro lado, gente que puede tolerar lo fragmentario y adoptar el psicoanálisis como un instrumento que permite pensar problemas sociales, pero dentro de un campo interdisciplinario y no asumiendo para sí la totalidad del saber.

\section{E: ¿Cómo ve la relación del psicoanálisis con la investigación cientifica hoy en dia?}

LH: Uno de los temas que se presenta es qué tipo de investigación, si la investigación cuantitativa o cualitativa... ahí entramos en un terreno complejo, yo creo que el psicoanálisis debiera tener vocación científica, quiero decir de ser intersubjetivo y de poder comunicarse. El problema que se abre ahí es el de qué tipo de investigación respetaría la complejidad del psicoanálisis, si métodos positivistas o si por el contrario algo que permita explicitar la clínica psicoanalítica, proponer conjeturas, etcétera. Yo no creo en un psicoanálisis esotérico intrasmisible, pero luego surge la discusión de a qué paradigma someter la investigación en psicoanálisis. Veo un campo verdaderamente problemático. 
Por otro lado, hay algo que nos pasa en Argentina que a veces no ponemos en contexto, es decir, voy a dar un ejemplo de lo que quiero decir. Pontalis en un momento dado comenta: "iqué ricos son los ingleses a nivel clínico, que sutiles...!", y es lo mismo que pensaron acá en la década del sesentasetenta; pero él le agrega una frase, que pareciera no haberse leído: “...claro, sus pacientes son distintos a los nuestros”. Si en Argentina la segunda parte hubiera sido tomada, nos hubiéramos dado cuenta de que no atendiamos pacientes psicóticos, como en Londres, o pacientes muy graves, sino que atendíamos a la señora que acababa de dejar a su hijo en el jardín de infantes o al ingeniero que venía a analizarse porque su mujer era psicoanalista... y entonces no hubiéramos incurrido en el error de tomar a los neuróticos como psicóticos. ¿Se entiende? Con esto lo que quiero decir, como ejemplo, es que tanto en Alemania, donde se hace un tipo de investigación en psicoanálisis, el psicoanálisis es financiado por el estado, con lo cual necesita recurrir a métodos que permitan que las indicaciones del psicoanálisis puedan ser avaladas por un presupuesto... Acá en Argentina tenemos otros problemas clínicos que los de hacer científico al psicoanálisis para que el estado pueda financiar los tratamientos psicoanaliticos. Entonces, me parece que en la investigación debe haber una economia de tratar de abordar los problemas que yo tengo que abordar y aceptar que hay otros países donde tienen otro tipo de problemas; entonces algunas discusiones teóricas, que acá son de eruditos, en Alemania son cruciales porque los tratamientos son financiados por el estado.

\section{E: Antes nos decia que no es muy optimista respecto al estado actual del psicoanálisis argentino, ¿cómo ve el futuro del psicoanálisis en nuestro pais, teniendo en cuenta su diversificación interna $y$ sus relaciones con otras disciplinas?}


LH: No tengo una visión pesimista con respeto al futuro... en la medida en que tomemos conciencia y seamos autocríticos: ¿por qué en lugar de encontrar un lenguaje que pudiera ser inteligible para todos los psicoanalistas y discutir problemas clínicos, cada vez más hablamos para la parroquia a la cual pertenecemos? A mí una vez me tocó algo muy absurdo, pero que para ustedes puede resultarles divertido, que era hablar de epistemología del psicoanálisis en la Asociación de Epistemología del Psicoanálisis. Con la particularidad de que en primera fila estaba sentado Gregorio Klimovsky, un profesor de epistemología de casi todos los analistas... yo era más joven y más audaz que ahora y había estudiado epistemología, mucho Alltuser y todo ese tipo de corrientes entonces dije: "un amigo mío solía pensar 'si nadie sabe portugués, voy a cantar una canción en brasilero', pero yo venir acá a hablar de epistemología ante usted Gregorio...", le dije, pero agregué "le voy a decir una cosa: si epistemología en una definición es teoría del conocimiento, dentro del psicoanálisis la epistemología del psicoanálisis es la teoría del reconocimiento, uno no escribe para conocer, sino para hacerse reconocer. Entonces cuando alguien escribe, uno sabe a quién está dirigido ese escrito, a través de la bibliografia misma, pero no tiene nada que ver con el conocimiento, sino con la pertenencia y con la identidad psicoanalítica". Me consta que le interesó tanto que lo repitió en varios lugares. Entonces yo diría acá, respecto al futuro del psicoanálisis, que los analistas tendrian que mirarse menos el ombligo y tratar de dar cuenta de las problemáticas clínicas de nuestro país. Cuando yo estudie medicina, lo que todos sabíamos que pasaba en los exámenes era que no te tomaban ni pulmonía, ni chagas, ni tuberculosis; te tomaban la enfermedad de Vezzet, la más rara. En los cursos de psicoanálisis, no se habla ni de borderline, ni de depresiones, se habla de fetichismo, de bestialismo... bueno ahora la pedofilia ha tomado un carácter importante, pero quiero decir: hay una discordancia entre la agenda clínica y la agenda teórica. La gente no habla de lo que ve todos los días en la clínica sino lo que para su grupo da 
prestigio. Esa disociación entre lo que es la práctica cotidiana y lo que se enuncia entre los colegas, empobrece, vuelve muy aburridas las reuniones entre psicoanalistas. Entonces, una de las primeras cuestiones que habría que tratar es primero tener un conocimiento adecuado, de la teoría freudiana y de algunos desarrollos post freudianos. Dentro de esos desarrollos post freudianos cada quien tendrá la libertad, o debiera tenerla, de incorporar como herramientas aquellos que le son más productivos. Segundo, empezar a hablar más de las practicas reales; Freud decía: "gris es toda teoría y verde el árbol de la vida"4, ¿por qué no hacemos más verdes los intercambios entre colegas, hablando de la vida de nuestros pacientes? La vida es mucho más interesante que los textos; los textos permiten entender a los pacientes, es como diria Marx: "ascender a lo concreto"5, no descender a lo concreto. Entonces muchas veces se confunde teoría con teoricismo, y se hace una metapsicología de la metapsicología de la metapsicología... y uno pierde de vista qué tiene que ver eso con la clínica cotidiana. Por ejemplo, hay muchos seminarios que llevan por título "teoría del fin de análisis"... Lo que habría que enseñar en Argentina es como se comienza un análisis. Si ustedes se toman el trabajo de leer la oferta de seminarios, son de temas totalmente alejados de la práctica cotidiana pero luego cuando uno asiste, ve que hablan de cosas que solo entienden los iniciados. Foucault habló de las sociedades de discurso, como esas sociedades tienen por eje mantener el prestigio de los recitadores, en lugar de los pensadores ${ }^{6}$. Hay mucha gente que recita la teoría, en lugar de reciclarla; si consiguiéramos que la gente tomara más conciencia de que tenemos una clínica compleja en Argentina,

\footnotetext{
4 Cf. Freud, S. (1924/2004). "Neurosis y psicosis". En: Obras Completas, tomo XIX. Buenos Aires: Amorrortu.

${ }^{5}$ Cf. Marx, K. (1894/1981). El capital. Critica de la economía politica. Madrid: Siglo XXI.

${ }^{6}$ Cf. Foucault, M. (1970/2013). El orden del discurso. México: Tusquets.
} 
con pacientes cuyo sufrimiento es importante ${ }^{7}$, que venimos de cuatro o cinco décadas donde predominaron las híper: híper-inflación, híperterrorismo de estado, híper-desocupación, híper-corrupción, y que eso tiene que ver con la práctica de todos los días, en la subjetividad de los analistas y en el sufrimiento de los pacientes; en vez de copiar solamente lo que está pasando en París o en Londres, etcétera. Habría que lograr esa mayor libertad a nivel de las referencias teóricas y lograr hablar de los problemas clínicos reales, asignándole a cada problema clínico la importancia que tiene en nuestra práctica cotidiana y no la importancia que tiene para otros autores en otros contextos. Miren, yo tengo muchos años de psicoanalista y nunca vi un fetichista, no vi ni uno. Nunca vi a un exhibicionista. Veo homosexuales, veo depresiones borderline, pero hay patologías que nunca vi. ¿Por qué no hablamos de las patologías cotidianas? Este sería otro paso en cuanto a convertir al psicoanálisis en un psicoanálisis más comprometido.

Tercer elemento, ¿por qué no hablamos más de la implicación subjetiva del analista?, no el analista como un muerto, no el analista como un espejo, sino como incide la historia del analista en el encuentro analitico. Por qué no hablamos de que no es posible tener un ideal tecnológico, donde uno es un técnico que opera, sino que uno es un intérprete comprometido con el otro y que el psicoanálisis es un encuentro entre dos subjetividades... donde, por supuesto, lo deseable es que predomine la problemáticas ligadas a la subjetividad del paciente, pero donde uno no puede dejar la propia historia y el propio inconsciente en el perchero antes de entrar a la consulta. Las ciencias ya no hablan de un observador no-participante, hablan de un observador implicado, complicado. Y mucho más en el encuentro psicoanalítico. Estos serían elementos para mantenerse más actualizados, lo mismo con respecto a la relación entre determinismo y

7 Hornstein acabo de publicar varios trabajos en Facebook.com/luishornstein, donde aborda en detalle estas temáticas. 
azar: ¿cuánto de la infancia es un destino y cuanto es una potencialidad?, porque hoy sabemos que los sistemas más complejos son menos predecibles. Yo puedo predecir mucho más en un paranoico grave o en un depresivo grave que en un paciente menos grave, porque en ese paciente menos grave, que es un sistema abierto, vamos a encontrar los duelos, vamos a encontrar los exilios, vamos a encontrar las relaciones que establezca, la propia historia. Los vínculos, las sublimaciones, los traumas, lo histórico-social. En suma: la realidad actual. Ello supone oponernos al solipsismo que predominó en algunas corrientes posfreudianas.

\section{E: Vamos a encontrar otra sensibilidad a las condiciones iniciales...}

Claro. Entonces, se trata de pensar al psiquismo como un sistema complejo, abierto. Un sistema abierto, auto-organizador que tiene por función convertir ruidos eventualmente desorganizantes en información complejizaste, pero esto implica, esto que vos decís, no solamente con respecto a las condiciones iniciales, sino con respecto a qué lugar tiene la realidad en las problemáticas actuales de un paciente, no solamente la historia infantil... porque a mayores fijaciones, más importancia de la historia infantil y a menor fijación, más determinante va a ser la realidad actual.

\section{E: Las teorizaciones sobre los sistemas complejos tienen un lugar importante en su pensamiento, ¿considera que constituyen una referencia fundamental para el psicoanálisis contemporáneo?}

LH: Para mí fue una apertura desde el año noventa, por la relación entre determinismo y azar, por la posibilidad de pensar a un sujeto no como un ser sino como un devenir, así como por el problema de la recursividad: pensar que la historia no es solo el pasado, sino que es desde el presente 
que se reactualizan ciertas potencialidades del pasado. En ese sentido, hay que saber que no operamos nunca con fenómenos simples en psicoanálisis; al acto fallido que parece más evidente hay que someterlo a la asociación libre, a la subjetividad singular de esa persona. Entonces, creo que la teoría de la complejidad no solamente viene a solucionar problemas, sino que viene a situarnos en el horizonte epistemológico actual, que no es el mismo que el de Freud ni el de Lacan.

Un Premio Nobel de física escribió "El Quark y el Jaguar", donde dice que cuando él descubrió el Quark, en ese momento la partícula más minúscula del universo, descubrió que dentro del Quark había un universo... es decir que se volvió un apóstol de la complejidad. Allí se muestra que no es como uno pensaría, que si la ciencia avanza llegará a dos o tres formulaciones... en ese sentido, como ustedes se dan cuenta, la ilusión del matema de Lacan corresponde a una epistemología de la simplicidad: hay en cada persona un matema último que sería el núcleo de su subjetividad, un fantasma fundamental. Freud daba como ejemplo de lo que es el trabajo analítico lo que los holandeses habían recuperado algunos metros al mar pero no habian conquistado el atlántico... y decía que el psicoanálisis se basa en lograr que haya un poco menos de inconsciente y un poco más de consiente que antes, pero que nunca se agotará lo inconsciente porque siempre aparecerán, decía en Análisis terminable e interminable, cosas nuevas que no pudieron ser analizadas porque solo se puede analizar lo que la vida actualiza. Y también decía, de paso, que no todo puede ser actualizado en la transferencia; por eso no hay análisis completo, sino que un análisis es un análisis de lo actualizado hasta ese momento y nadie puede pronosticar el futuro... él decía: a lo sumo se puede decir que uno pone en mejores condiciones al sujeto para enfrentar la vida que antes, pero no podemos predecir lo que le va a pasar al sujeto en la vida. Ahora fijense como contrapartida: cuando yo me empecé a formar, estaba la primera entrevista que podía servir para revelar no solamente el futuro de un análisis sino el futuro de una vida. Pero eso no fue nada en la escala de 
ortodoxia: después fueron los primeros cinco minutos, en los que ya estaba todo... después se siguió: ya no eran los cinco minutos, era la llamada telefónica... ahora ¡fijense la ilusión que es propia de un sistema simple!, cuanto más simple es un sistema, más predictible es. Yo puedo planificar los muebles de mi consultorio, puedo hasta hacer un country y planificarlo; pero no una ciudad, porque viene un George Soros y decide convertir Almagro en Puerto Madero, y ya está. O vienen los peruanos y se instalan en tal lugar... Digo, no se puede predecir en fenómenos complejos más que renunciando a la predictibilidad y sustituyéndola por la probabilidad. Esto es paradigma de la complejidad. ¿Yo puedo decir que tal madre va a producir tal hijo?, no. Puedo decir que hay más probabilidad, pero no puedo predecir. Salvo que esté manejándome con sistemas simples. Por eso la pregunta sigue siendo: ¿es el azar una falta de conocimiento o un hecho de la naturaleza? En un paciente, ¿cuándo va a jugar más el azar?, cuanto más sea un sistema abierto; y ¿cuándo va a jugar menos el azar? En un melancólico grave o en un paranoico, donde pase lo que pase nada entra; como en las computadoras que te dicen "syntax error". Ahora fijense que en esa época donde yo me formé era la idea que en cinco minutos ya se podía predecir mediante la llamada telefónica... ¡hubo congresos sobre esto! y a nadie se le ocurrió decir con contundencia que una primera entrevista es como un sueño, es un contenido manifiesto, cuyo contenido latente se desplegará en meses de análisis... y cuando el paciente habla de su sueño con el tío José, ¡yo no sé quién es el tío José! a lo menor después de veinte sesiones recuerda que al tío José le gustaba jugar con él cuándo él tenía cuatro años y lo toqueteaba... ¿y cómo voy a saber yo en la primera entrevista? Entonces esto tiene que ver ya no con simplemente intentar estar a la "moda" con respecto al horizonte epistemológico actual, sino que tiene que ver con la complejidad de cada clínica. Hay gente que sigue creyendo que poniendo un diagnostico ya está todo claro, cuando el diagnóstico es un punto de partida, no un punto de llegada; y se convierte en algo resistencial cuando 
esa persona cree que porque pone un diagnostico ya sabe quién tiene enfrente y ya puede pronosticar el futuro de ese paciente. Quiero exceptuar de esto a los pacientes más graves: el diagnostico sí tiene vital importancia en la esquizofrenia y en un trastorno bipolar. Pero cuando entramos en el campo de la neurosis, el diagnostico se convierte en un auxiliar para empezar a pensar problemas... y lo más probable es que a pocos pacientes les quepa un diagnostico sólo, sino una pluralidad de diagnósticos.

De lo que se trata es de poder pensar que el inconsciente que nos interesa es el inconsciente que esta actualizado y produciendo efectos, al inconsciente que no está actualizado Freud lo llamaba "conflictos pulsionales latentes" y decía que algo despertaba a "los perros dormidos"8, ya sea la realidad, lo que está viviendo, el refuerzo pulsional, la disminución de las defensas cómo durante el dormir o en la depresión, etc., entonces surge lo inconsciente, el conflicto pulsional latente se despierta y pasa a ser un "conflicto pulsional actual". Esto muestra la importancia que tiene el presente en cuanto productor de esas actualizaciones del inconsciente, en oposición a pensar que la actualidad no es más que un pretexto para que uno proyecte el pasado sobre el presente, como si el presente no tuviera envergadura propia ¿no? Lo cual es cierto en un paciente muy grave que forma un sistema cerrado donde no ingresa ningún ruido. Pero en lo demás, pensar sólo en el pasado es una forma de determinismo lineal, que no contempla nada nuevo que el presente pudiera agregar al pasado; y que conduce a hablarle al paciente todo el tiempo de lo que pasó allá lejos en el tiempo... esto generó mucha insatisfacción clínica por parte de la gente. A mí me viene a ver gente que me dice: "no, yo ya me analicé muchos años... no quiero análisis", y cuando les pregunto por qué, me dicen: "no, porque quiero hablar de mis

8 Cf. Freud, S. (1937/2004). "Análisis terminable e interminable”. En: Obras Completas, tomo XXIII. Buenos Aires: Amorrortu. 
problemas actuales". ¿Acaso Freud no escribió "Recuerdo, repetición y elaboración"?, ¿acaso no dijo que lo único del inconsciente que nos interesa es lo que esta actualizado? Lo importante no es que me hable de la madre, lo importante es que hable de su relación con su pareja actual, a partir de lo cual es posible que busque en el pasado formas para entender mejor el presente, pero lo que a mí me interesa es trabajar sobre las problemáticas actuales de una persona... ¡no a mí, a Freud!, entonces esos tipos que dicen "yo quiero hablar de mis problemas actuales, no de lo que paso... del pecho, mamá, papá, el S, el S2 o la pulsión...”, eso es lo que yo veo en el lacanismo: una fuga a la abstracción, no un acenso a la abstracción. La queja de la gente es que el paciente queda desdibujado y lo que empieza es una clase teórica acerca del Edipo, el falo, la castración, la pulsión de muerte, el goce, pero no se habla de éste superyó...

\section{E: Sabemos que se ha ocupado bastante del tema de las depresiones, publicando un libro y varios artículos'. En el ámbito psicoanalítico local pareciera que tus aportes al tema han sido muy bien recibidos, ¿podria comentarnos brevemente algunas de sus ideas al respecto?}

LH: En primer lugar, la OMS nos dice que la depresión actualmente es la cuarta causa de muerte y discapacidad a escala mundial; y se estima que ocupen el segundo lugar para el 2020. Y eso que la OMS no habla de Argentina sino de países muy estables... no habla del tipo que se jubiló y que recibe una jubilación minima y que depende de su hijo, ni habla del tipo que no sabe si el mes que viene va a poder pagar la prepaga... con lo cual, seguramente si hubiera estadisticas confiables en Argentina, seria más alarmante el dato. Una vez di un curso en una maestría y recuerdo que una chica que había sido jefa de residentes de un hospital, me decía que en toda su práctica ella "nunca había hecho el diagnostico de

\footnotetext{
${ }^{9}$ Hornstein, L. (2006). Las depresiones. Buenos Aires: Paidós.
} 
depresión" y que, además, según ella "Freud no había hablado de depresión" y que "no tiene estructura la depresión". Cuando Freud escribe "Neurosis y Psicosis" en el año 24', habla de tres problemas distintos: uno donde el conflicto es entre el Ello y el Yo, neurosis, otro donde el conflicto es entre el Yo y la realidad, psicosis, y la tercera donde el conflicto es entre el Superyó y el Yo, y las llama neurosis narcisistas a esas; entonces justamente: la depresión tiene una estructura de un conflicto que a nivel tópico es el conflicto entre el Superyó y el Yo. A mayor distancia entre los ideales del Yo, Superyó y el Yo, más probabilidades hay de que uno hable de una depresión... si la angustia frente a la perdida de amor del Superyó es lo predominante o estamos en frente a una obsesión o una depresión. Freud habla además de los estados depresivos en "Inhibición, síntoma y angustia" y habla de duelo y de melancolía... entonces pensé: "no sé qué habrás hecho vos con tus pacientes...". Yo creo que esto ha pasado muchas veces en psicoanálisis. Hasta hace poco el lacanismo negó la presencia del síndrome borderline, lo tuvieron que recauchutar después, pero existía: psicosis, perversión o neurosis... y se hablaba nada menos que de pre-psicosis, con la indicación de Lacan de que un pre-psicótico no podía ser analizado... sí un psicótico, lo cual es una barbaridad. Por eso Piera Aulagnier, en lugar de hablar de estructura psicótica, habla de potencialidad psicótica ${ }^{10}$, refiriéndose a alguien a quien, de sucederle ciertas cosas, puede llegar a tener una psicosis clínica. Entonces, ¿por qué la depresión? Porque es cotidiana la depresión y está incluida en nuestra práctica clínica. Yo no llamo depresión a alguien que tenga oscilaciones en la autoestima, como tiene toda persona... recuerdo una vez que me invitaron a escribir sobre el trastorno bipolar y yo iba a ponerle de título "la bipolaridad hasta en la sopa"... porque se llama trastorno bipolar a cualquier cosa, en lugar de hablar de la hablar de la ciclotimia, en tanto

10 Aulagnier, P. (1986/2003). El aprendiz de historiador y el maestro-brujo: del discurso identificante al discurso delirante. Buenos Aires: Amorrortu. 
que oscilaciones del humor... entonces ¿por qué la depresión?, porque es la única patología que compete a nuestra practica que está entre las primeras cinco causas de discapacidad según la OMS, incluso después de los trastornos cardiovasculares... ¿y los psicoanalistas no hablamos de eso?, ¿le dejamos la depresión a los psiquiatras?, porque cuando uno no aborda un tema así, se lo está entregando, en este caso, a la industria farmacéutica... le está entregando el tratamiento de la depresión. Una de las cosas que yo discuto en ese libro es la indicación de antidepresivos en las depresiones leves y moderadas, porque no está demostrada su eficacia; salvo en las depresiones graves, que son el trece por ciento de las depresiones. Y si la industria farmacéutica facturaba en el 2010 o 2012 diez mil millones de dólares en antidepresivos en Estados Unidos, tendría que facturar mil trecientos millones de dólares. Entonces ahí estamos frente a una polémica, que ya no es una polémica de ideas, es una polémica donde hay mucho poder económico del otro lado. No se debe considerar a la depresión desde un reduccionismo biologicista, como un problema biológico, un problema de moléculas... ¿y los duelos?, ¿y la construcción del yo?, ¿la construcción del Superyó, los valores, las situaciones sociales? Un jubilado, como les decía hace un rato, que para poder fumar un pucho tiene que pedirle a su nuera para comprar cigarrillos, un tipo que ha trabajado toda su vida... ¿biológico? Entonces, no encarar problemáticas como la depresión, es renunciar ante la industria farmacéutica y entregarle una patología que debe ser recuperada como problemática psíquica de sufrimiento ligado a la historia, a los duelos, a la problemática subjetiva de cada quien. Hoy mucha gente sigue pensando que la depresión es un problema de moléculas, pero ¿qué depresión?, en la depresión mayor si; pero aún en la depresión mayor si no hay un terapeuta que pueda tener un cierto tipo de vínculo, no tiene eficacia el tratamiento medicamentoso. Entonces, es reivindicar la subjetividad frente a la potencia de la industria farmacéutica que quiere convertir a los psiquiatras en simples gatillos fáciles para la medicación; y 